\title{
Subjetividades Femininas em Teolinda Gersão e Inês Pedrosa
}

\author{
Maria Lúcia Wiltshire de Oliveira (UFF)
}

\section{RESUMO}

Nosso interesse é descrever e discutir o pensar, o sentir e o agir de personagens femininas na narrativa de ficção das duas autoras portuguesas, buscando detectar nessas representações do feminino subjetividades diferentes que procedem de distintas gerações, em paralelo com uma "zeitgeist" respectivamente moderna e pósmoderna, segundo a visão de alguns teóricos contemporâneos.

Palavras-chave: Teolinda Gersão, Inês Pedrosa, Literatura e Gênero, romance português.

"Não há outro valor por que lutar senão pela liberdade de inventar a esperança, aceitando a possibilidade do desastre (...)." Teolinda Gersão ${ }^{1}$

1. $\mathrm{Na}$ antiga terminologia escolástica, "subjetivo" é referido muitas vezes ao existente em si mesmo como ente real, o que está em relação com o sujeito, em contraposição ao objeto. De procedência filosófica, o termo migrou para a Psicologia no final do século XIX, tornando-se o objeto da nova ciência em substituição à alma como atributo inerente ao sujeito. Embora se possa falar de uma subjetividade expressa em comportamentos, ela se aplica com mais propriedade a pensamentos e sentimentos que não só explicam as ações do sujeito, mas sobretudo evidenciam o embate de uma interioridade com o mundo exterior. Apesar de sua dimensão aparentemente singular, não se trata de uma categoria desvinculada da objetividade porque se forja no jogo com o tempo individual e histórico.

Os estudos lingüísticos destituíram a aura do cogito cartesiano - "penso, logo existo" - em que o sujeito era visto como uma essência anterior ao pensamento e independente da linguagem. Inscrito necessariamente no discurso, o sujeito enuncia sempre algo para alguém, instituindo-se um Tu e um Ele simultâneos ao Eu e à ação de pensar, numa rede inelutavelmente triádica, como bem demonstrou Benveniste. A expressão "intersubjetividade", muito usada para designar a relação diádica e especular com o Outro (primariamente a Mãe), é incompleta pois deixa de lado o terceiro termo, associado ao Pai ou ao Simbólico, que corresponde ao Ele na constituição do sujeito em psicanálise. Enfim não há subjetividade sem sujeito, não há sujeito sem discurso, não há discurso sem destinatário e sem objeto. ${ }^{2}$

Como mostram vários críticos, a obra de ficção é capaz de delimitar uma subjetividade uma vez que encena uma aventura com início, meio e fim, onde um sujeito - como parte de um discurso - se constitui diante do leitor (atuando para ele), na sua relação com outros eus e o mundo diegético ficcionados. D. Quixote é a representação de uma determinada subjetividade pois ainda que muitas interpretações 
de suas ações o tornem polivalente, trata-se de uma polivalência concluída e da qual se pode falar. $\mathrm{Na}$ vida real só se pode dizer da subjetividade de alguém depois da sua morte ou então através do discurso biográfico ou autobiográfico que "mata"o sujeito real e estabelece o sujeito ficcionado. De todo modo, nos dois casos é impossível concluir sobre a subjetividade de um ser, pois mesmo se o "eu" se torna completo e finito num texto, o mesmo não se pode dizer do "tu" da relação, cuja leitura pode variar ad infinitum. Também a psicanálise trabalha com a noção de um sujeito em devir, avessa à idéia de uma subjetividade concluída mesmo ao fim da análise.

Para além do plano pessoal, estudos interdisciplinares investigam hoje "formas de subjetivação" próprias aos homens e às sociedades ao longo do tempo. Em especial a história das mentalidades manipula o conceito em cortes epistemológicos segundo uma visão retroativa do fenômeno. Como se constata, o discurso científico assim como a ficção envolvem um distanciamento na consideração da subjetividade, não apenas como um atributo do sujeito, mas para significar uma sensibilidade hegemônica, própria a uma época e a uma sociedade, passível de representação metafórica, metonímica ou alegórica na obra literária.

2. Sob tal perspectiva poderíamos levantar a hipótese de uma subjetividade moderna e de uma subjetividade pós-moderna, detectáveis na sociedade e representadas problematicamente na literatura. Segundo $\mathrm{Hassan}^{3}$, o moderno se contrapõe esquematicamente ao pós-moderno sob vários aspectos. Assim, do lado do moderno estão a transcendência, o propósito, o paradigma, a determinação, o significado e a profundidade; e do lado do pós-moderno estão, em contraponto, a imanência, o acaso, o sintagma, a indeterminação, o significante e a superfície. Também Bauman menciona uma forma líquida e leve de ser que se opõe ao modo sólido e pesado da modernidade. Como precursor da reflexão sobre o pós-moderno, Lyotard coloca a deslegitimação das metanarrativas no fulcro dessa modernidade tardia que varreu as certezas sobre o mundo.

$\mathrm{Na}$ passagem do moderno ao pós-moderno, eclodiram os movimentos das minorias expressando o paradoxo entre a identidade e a pluralização do eu. $\mathrm{O}$ feminismo foi um desses fenômenos contraditórios que tanto invocou uma diferença essencial para o feminino quanto defendeu uma identidade historicizada de gênero para a mulher. Em ambos os casos manteve-se a crença numa oposição ao masculino, o que aponta para uma problemática que não desenvolveremos neste trabalho apesar de tratarmos de mulheres.

O interesse aqui é observar as representações de uma subjetividade moderna e pós-moderna reconhecíveis em personagens femininas, respectivamente de Teolinda Gersão e Inês Pedrosa. As duas autoras contemporâneas pertencem a gerações distintas, já que a primeira nasceu nos anos 40 e a segunda nos anos 60. Considerando que o pertencimento a uma geração se articula à época em que se dá a formação do jovem, geralmente em torno dos 20 anos, temos que Gersão é da geração de 60, das revoltas estudantis de "maio 68", enquanto Pedrosa é da geração de 80, marcada pela queda do muro de Berlim e pela globalização. No cenário interno, foi sob o influxo do momento pós-revolucionário que Teolinda Gersão, no início da década de 80, começou a publicar suas obras que perfaz oito romances e um livro de contos. Por sua vez, foi no bojo da segunda onda do boom narrativo português ${ }^{4}$, em 1992, que Inês Pedrosa publicou seu primeiro livro de ficção, a que se seguiram mais dois romances e um volume de contos.

3. As protagonistas de Teolinda Gersão são mulheres à beira da libertação, movidas por uma força transgressora. Lídia de O silêncio (1981) é uma jovem que ofende as normas 
sociais ao se tornar amante de um homem casado com o qual almeja realizar uma relação harmoniosa e eqüitativa. No entanto, Afonso é mais velho, de uma geração de homens de vida ambivalente, embora não seja mais o macho autoritário do passado.

Não é um marialva como o Engenheiro Palma Brava de O Delfim, mas ainda se pauta por uma ética amorosa desigual entre os sexos. Lídia consegue perceber os equívocos desta relação e a repudia em direção a um futuro não definido, deixando a casa, sob o olhar odiento do amante que não compreende sua coragem. Do alto de quinze andares, ele via a mulher se afastando de si, desprezando seu amparo,

De repente fora do seu alcance, caminhando, abrindo passagem com o corpo, uma pequena figura entre outras (...) na rua, onde uma pequena multidão avançava (...) (GERSÃO, 1984, p. 124)

Semelhante destino é escolhido por Vitória de Cavalo de sol (1989) que ao final do romance abandona a casa dos tios sem direção certa, libertando-se de um noivado com o primo rico que, ao final, sucumbe ao próprio machismo, vitimado pela tirania da masculinidade, como nos ensina Boudier. Graças à prática da liberdade na equitação e à estreita relação com a natureza, Vitória se torna imune às mesquinharias do meio familiar, alçando-se a um outro patamar em que a imaginação é a ferramenta de propulsão para uma outra vida, numa "cidade iluminada" que ela via no fundo do ribeiro (GERSÃO, 1989, p. 54). Antes que se soubesse do suicídio de Jerônimo na Casa em que moravam, ela partia "sozinha para o desconhecido e enfrentava o mundo como se ele não fosse selvagem" (GERSÃO, 1989, p.213), identificando-se ao cavalo "como se saltasse uma barreira" (GERSÃO, 1989, p.214).

Também Gita, de Árvore das palavras (1997), depois de viver uma experiência amorosa iniciática e frustrada com Rodrigo, um filho-de-família rica de Lourenço Marques, resolve trocar sua cidade por Lisboa onde sabe que precisará de coragem para superar as adversidades de sua origem africana como filha mestiça e sem dote na casa dos tios brancos portugueses. Atingida pela guerra colonial, ela vive com os colegas de liceu o sonho da liberdade ao pintar num cartaz de protesto uma simbólica "árvore das palavras" contra o regime opressor. No entanto, no plano pessoal, Gita se decepciona com o namorado que a despreza ao imaginá-la grávida de si. Com a dor, vem a lucidez mesclada ao desejo utópico:

A independência, repito, fascinada, como se até aí não tivesse percebido que é disso, finalmente, que se trata: Um dia é-se livre, e já não se depende de ninguém. (...) Como este país. E ao mesmo tempo que ele. Sorrio pensando no cartaz e na frase que deixamos sobre o muro. (GERSÃO, 1997, p. 218)

No caso de Hortense, de Paisagem com mulher e mar ao fundo (1982), não se trata de libertar-se de um homem, mas dos tentáculos de O.S. (Oliveira Salazar) e do luto frente a perda do marido e do filho vitimados pelo regime. Hortense hesita diante da possibilidade de se libertar da dor e da revolta pois para se destruir "bastava abrir o frasco de comprimidos" (GERSÃO, 1985, p. 11). Experimenta a sensação de que tudo está a diluir-se, a indiferençar-se, num sem sentido de gestos e palavras que a fazia "Oscilar entre a janela e a porta”(GERSÃO, 1985, 13-14). Refugiada nesse pequeno mundo, que é sua casa e sua interioridade, ela vive na ante-câmara da morte pelo silenciamento das vozes. A certa altura algo em si clama pela saída, acreditando que "deveria haver algures um ponto de fuga" (GERSÃO, 1985, p. 17). Subitamente ela se liberta do torvelinho e pensa com terror na sua falta de compaixão: Clara, sua nora, viúva e grávida, também sofre. Ao pensar na outra, Hortense está a um passo da cura de sua depressão, politicamente motivada, graças ao possível exercício da solidariedade. 
Liberta-se da dor pela palavra de afeto e esperança que lança à mãe do seu futuro neto.

Júlia de Os teclados (1999) e Ilda de Os anjos (2000) têm também perfis transformativos. Ambas são adolescentes que cumprem um ritual de iniciação para uma vida adulta lúcida. Júlia encontra a arte como forma de realização, fazendo da música o seu destino acima de qualquer outro, sobretudo daquele vivido pela tia que sofria sob a dominação masculina. No entanto,

\begin{abstract}
Sabia por exemplo que teria amantes. O seu corpo sabia. Mas não iria deixar-se prender por nenhum deles (...) Ou talvez o contrário: nenhum dos amantes se fixaria nela, todos a iriam abandonar, um após o outro. $\mathrm{O}$ teclado ocupava demasiado lugar na sua vida, dir-lhe-iam sempre finalmente. E odiá-la-iam por isso. Mas ela não abandonaria o teclado por amor a nenhum deles. (GERSÃO, 1999, p. 79)
\end{abstract}

Ilda, a narradora de Os anjos, é a representação promissora de uma nova mulher em formação que saberá aceitar a possibilidade de felicidade amorosa para fora dos enquadramentos sancionados pela sociedade, a exemplo do que se deu com sua mãe que, para evitar a histeria e o desequilíbrio familiar, contou com a aquiescência do marido e do sogro para regularmente queimar-se de amor na casa do ferreiro Serafim.

Já a anônima autora do falso diário chamado Os guarda-chuvas cintilantes (1984) é uma mãe de família classe média, às voltas com a educação familiar e a necessidade de praticar a escrita de cada dia como um modo de sobreviver. Este exercício é um embate com o cotidiano doméstico onde a mulher "tem sempre as mãos ocupadas com outras coisas, panos de cozinha, lençóis, legumes (...) uma infindável multidão de coisas" (p. 83) que se intrometem entre a sua mão, a caneta e o papel.

Todas estas protagonistas ultrapassaram a paixão pelo homem como sentimento justificador de suas existências. Todas adotam doravante a paixão por si mesmas como forma de recuperação da auto-estima que as gerações anteriores interditaram à mulher. Todas pertencem à geração de 68 , paradigma de libertação utópica que sacudiu a França e o mundo, marcando o início das grandes alterações de mentalidade nos países de cultura ocidental, com fortes repercussões nas minorias e nas feministas. Lídia,Vitória e Gita recusam abdicar de si em nome do amor-paixão, embora o tenham experienciado em certo período de suas vidas. Suas subjetividades são vincadas pela coragem, qualidade heróica que as leva a enfrentar o mundo desconhecido com um otimismo narcísico, dispensando a paixão e a presença de um homem que as apóie. Já Hortense e sua nora Clara, irmanadas pela dor da perda de seus homens, vítimas da ditadura, reconstroem seus eus dilacerados através de uma relação de amizade, se calhar a mesma que desfrutavam com seus parceiros em oposição ao regime que, então, representa o obstáculo à realização de todos ${ }^{5}$. Por sua vez, com Ilda e Júlia, ambas muito jovens, a realização pessoal não passa por uma recusa do macho, mas da cultura machista que normatiza os comportamentos. Por fim, a voz cintilante dos guarda-chuvas não nutre nenhuma obsessão de amor romântico e, ao contrário, vive a paixão da escrita sem pensar nos "louros" do reconhecimento literário. Com "a pequena escrita quotidiana, [pretende] deixar um risco no tempo, um traço na areia, para provar que [está ] (...) viva" (GERSÃO, 1984, p. 23). Movida por certeza e determinação, a escrita é o passaporte para a construção da subjetividade - ela diz: "De fato, alimento-me das possibilidades de uma língua" - , o que nos leva a pensar que esta personagem anônima seja o mais próximo alter ego da autora ${ }^{6}$. Representaria ela a mais apurada subjetividade, a que se exerce no verbo e pelo verbo?

Todas estas mulheres estão movidas por um projeto utópico em que a 'transcendência' da condição servil é o objetivo do processo libertador que se ajusta a um "propósito" de alteração de "paradigma", em que a "determinação" da coragem 
pode levar à "profundidade" de suas essências, negadas ou oprimidas. São mulheres com um modo sólido de ser, exemplos de vida para as personagens secundárias que a rodeiam e que estão submetidas à ordem cultural dominante. Tais subjetividades são marcadas pela crença em algumas metanarrativas: a da libertação feminina, a da libertação pela arte, a da libertação política frente aos regimes totalitários. Por detrás dessa investida libertária, estão os valores clássicos que balizaram a modernidade desde o século XVIII sob a pena iluminista da Razão, compondo um perfil épico de subjetividade.

4. As protagonistas dos romances de Inês Pedrosa se mostram de outro modo, revelando formas de subjetivação forjadas nos últimos 20 anos. No primeiro romance, cujo título $A$ instrução dos amantes é uma amarga ironia sobre o amor nos tempos pósmodernos, a protagonista é flagrada no momento de sua adolescência quando ferve de paixão por Dinis, um sujeito que não atende as suas expectativas amorosas. No entanto, apesar de fugir ao estereótipo das mulheres dominadas pelo macho, apesar de dispor de toda liberdade para ficar ou não ficar com o amado, Cláudia insiste em se fazer amar como se isso fosse a única forma de dar sentido à vida. Ela pedia que o rapaz lhe mentisse dizendo "Amo-te", mas ele apenas a desejava eventualmente. Assim também procedem suas colegas Isabela e Teresa, todas voltadas para o amor-paixão como a suprema realização do ser. É desilusão após desilusão. Ao final do romance e da relação amorosa, não há uma libertação da personagem. Ao contrário, apesar dos muitos amantes que terá, ela alimenta na memória e nos sonhos a paixão não correspondida:

\begin{abstract}
Claudia fecha os olhos e vê-se uma vez mais nos braços dele. Quantos homens a amaram com eficácia e surpresa e originalidade, depois? Todos. Um cardápio de homens dignos dos padrões de qualquer revista, atléticos, simpáticos, sensíveis. E Cláudia a fechar os olhos para encontrar o rosto de Dinis sobre o tempo. (PEDROSA, 2006, p.163)
\end{abstract}

A personagem acredita na "imanência" dos acontecimentos, mas hesita em aceitá-la; entende que a vida é fruto do "acaso" mas se aferra com voluntarismo a um amor problemático talvez para negar o aleatório; rende-se à "indeterminação" dos afetos, considerando como conjunturais o amor a Dinis e a amizade à Isabel, mas cultiva a melancolia masoquista da saudade de ambos; busca entender a paixão pelo outro como afecção de "superfície", mas no entanto a preserva na profundezas da alma. Os embates sem solução acabam por esgotá-la:

Claudia está (...). Tão cansada e vazia que confunde as saudades de um amor com o desejo do amante que a decepcionou; cansada demais para perceber que o seu vazio tem o contorno infinito da disponibilidade (...) Ela ainda ama o homem que a desiludiu (...) (PEDROSA, 2006, p. 164).

No romance seguinte, Nas tuas mãos (1997), desfilam diante do leitor três subjetividades distintas que correspondem a três gerações sucessivas de mulheres. A primeira, Jennifer, se expressa na forma "antiga" do diário, mostrando a humilhação (ou a grandeza) de um casamento branco em nome da paixão a um homem (António), enfeitiçado por outro (Pedro), com o qual o casal convive sob o mesmo teto. A decepção na noite de núpcias não a conduz a revolta ou a desejos de libertação, pois Jenny fora talhada para a resignação típica das mulheres portuguesas do anos 40, fortemente atravessados pelos valores da família tradicional e pela ética do "não parecer mal". Ou então, ela é por demais avançada para a época já que aceita a homosexualidade do marido sem abrir mão da paixão, agora sublimada, que lhe dedica. A segunda mulher é Camila, fruto de uma outra relação de Pedro, que Jenny acolhe como sua própria filha. Ela pertence à geração transgressora de 60 que se expressa em comentários sobre suas próprias fotos. Como fotógrafa destemida, corre riscos no front 
para obter imagens da guerra colonial, acabando por se envolver com um militante negro da FRELIMO que morre depois de plantar em seu corpo a semente da mulher que aqui mais nos interessa destacar: Natália.

Herdeira de duas raças e culturas, sem problemas de identidade racial, ela é uma jovem arquiteta formada em Lisboa na década de 80, com um perfil de subjetividade semelhante ao de Cláudia do romance anterior. Como se fosse uma Cláudia adulta, não se trata mais de uma adolescente burguesa frente a escolhas amorosas, mas de uma profissional que hesita existencialmente entre o mundo da mãe, o da avó e o que vê diante si. Esta oscilação de valores está representada na figura do amante Álvaro que faz amor para nela encontrar a salvação e "logo a seguir se escoar como areia entre os [seus] (...) dedos"(PEDROSA, 2005, p. 154). Sempre modalizando seu discurso pelo "talvez", ela pensa que

(...) talvez seja, também ele, um produto desse regime de indiferença e regurgitação a que chamamos pós-modernidade, que parece aderir como uma luva ao longo hábito de languidez cultivado em Portugal. (PEDROSA, 2005, p. 154)

Em outro momento ela o aproxima da geração da mãe:

Talvez o Álvaro pertença ainda à geração da minha mãe, que foi delapidando um a um os 'grandes sentimentos'. Tinham medo de (...) se deixar possuir pelas pieguices do demônio da Estupidez (...) Fugiram dos caminhos da felicidade que lhes trazia temíveis ecos de respeitabilidade. (PEDROSA, 2005, p. 153)

Nas cartas que escreve à avó postiça (e não à mãe de sangue), a personagem fala da "paixão como método de alheamento" (PEDROSA, 2005, p. 154) praticado pelo amante e quiçá por si mesma. Consciente das mudanças culturais nos últimos tempos, ela deplora o fim das amizades que foram substituídas pelo mal estar da vida presente sob a tirania do dinheiro e da competição:

Logo que se entra para a Universidade percebe-se que a vida não perdoará a quem não se esfolar. Bem sei que no seu tempo não era assim. Nem sequer no tempo da minha mãe. (...) No princípio dessa década de oitenta que morreu há cinco dias, tínhamos tempo para noites infindas de conversa. Agora esfalfamo-nos a pensar que aos trinta e cinco vamos ter tempo outra vez" (PEDROSA, 2005, p. 156).

Embora se inspire na avó e se irrite com a mãe, Natália não deixa de admirar as qualidades desta última, revelando uma insegurança ou ambivalência própria ao caráter pós-moderno:

Critico-a muito, sim, e é verdade que quase tudo nela me irrita, mas tenho sobretudo um medo pânico de não lhe conseguir chegar aos calcanhares. A Camila resistiu à prisão e à tortura, e eu tremo só de pensar em dar sangue (PEDROSA, 2005, p. 151).

Apesar de toda esta lucidez, a paixão galvaniza Camila mesmo sabendo que a desilusão é inevitável. Ela se divorcia de Rui, rompendo uma relação morna para mergulhar de novo na relação complicada com Álvaro, com o qual não quer se casar pois descobriu com as mulheres da família que "ficar só é um privilégio de amante" (PEDROSA, 2005, p. 220). Ela acredita que "toda a experiência do amor tem o gosto melancólico de uma simulação", já que o amor é uma entidade exilada que roda "no vazio de um firmamento demasiado alto" (PEDROSA, 2005, p. 220). Estas três mulheres do romance escrevem, mas não tematizam o ato, como faz a heroína de Teolinda Gersão, talvez porque também abandonaram a utopia da escrita.

Por fim, a voz feminina de Fazes-me falta (2002) é a de uma professora de história, doublé de deputada, que vivia sozinha, sem marido, sem complexo de solteirona, 
cultivando amores avulsos. É uma mulher independente, bem realizada, que sofre com a miséria e a dor do mundo e não com suas paixões amorosas. No entanto, em algum momento, assoberbada pelo ritmo competitivo de trabalho, até então prerrogativa dos homens, não consegue escutar a voz do próprio corpo e adoece, fatalmente atingida por uma gravidez tubária não-planejada, mas talvez inconscientemente desejada. Ela sucumbe à paixão maligna pelo parceiro que nela semeou a morte e deste mórbido lugar (que na verdade é iluminado), como uma defunta-autora, ela emite sua voz em contraponto à voz do amigo / pai, num dueto elegíaco que estrutura a narrativa com originalidade.

Como se pode observar, as personagens de Inês Pedrosa aqui destacadas têm pontos em comum. Estão imersas no turbilhão da vida, mas paralisadas por uma paixão não curada e até mesmo deletéria que as imobiliza, podendo levá-las à destruição de si mesmas. São mulheres liberadas que se confundem com homens na vida pública, mas que estão ainda submetidas a uma servidão sentimental voluntária, talvez numa forma de experimentar a angústia do vazio de suas desimportâncias existenciais. Já não fazem mais o papel de "rainhas do lar" mas também não acreditam em histórias de reis e rainhas, acabando por amargar uma identidade que não se especifica enquanto tal. Podemos dizer que são subjetividades pós-modernas vivendo, na "imanência" de suas vidas, o "acaso" dos acontecimentos, conscientes da "indeterminação" das escolhas, sob os fluxos da "superfície". Se desistiram das utopias, pelo menos não perderam a capacidade de pensar o mundo, preservando os valores e conquistas de suas antecessoras. Ao aceitar "a possibilidade do desastre", oxalá elas não desistam "de inventar a esperança".

5. Claro está que as criações ficcionais das duas autoras rejeitam o estatuto histérico da Luísa de $O$ primo Basílio. São mulheres liberadas graças aos novos costumes do pósguerra, ao feminismo, à queda dos regimes ditatoriais, à entrada no mercado de trabalho, etc. As de Teolinda Gersão se afastam do perfil trágico de Emma Bovary, projetando no futuro uma vida promissora, ainda que independente do amor-paixão. Mas nas vozes femininas de Pedrosa ouvem-se os acordes trágicos de um desamparo que treme no ar sem solução, saudoso da amizade ou da paixão, ao contrário do clima otimista que finaliza os romances da primeira. É possível que na ficção de Pedrosa desfilem as filhas das protagonistas de Gersão, expectantes sem expectativas na cena anti-épica da modernidade tardia. 


\section{REFERÊNCIAS}

BAUMAN, Zygmunt. Modernidade líquida. Rio de Janeiro: Jorge Zahar Ed., 2001.

BOURDIEU, Pierre. A dominação masculina, $3^{\text {a }}$ - ed., Tradução de Maria Helena Kühner, Rio de Janeiro, Bertrand Brasil, 2003.

BRUGGER, Walter. Dicionário de Filosofia. São Paulo: Editora Herder, 1962.

GERSÃO, Teolinda. O silêncio. 3. ed. Lisboa: O Jornal, 1984a.

Os guarda-chuvas cintilantes. Lisboa: O Jornal, 1984b.

Paisagem com mulher e mar ao fundo. 3 ed. Lisboa: O Jornal, 1985.

Cavalo de sol. Lisboa, Publicações Dom Quixote, 1989.

Árvore das palavras. Lisboa: Dom Quixote, 1997.

Os anjos. Lisboa: Dom Quixote, 2000.

. Os teclados. 2.ed. Lisboa: Dom Quixote, 2001.

HARVEY, David. Condição pós-moderna, uma pesquisa sobre as origens da mudança cultural, 5. ed. Loyola: São Paulo, 1992.

LYOTARD, Jean François. A condição pós-moderna.2.ed. Lisboa: Gradiva, 1989.

PEDROSA, Inês. A instrução dos amantes. São Paulo: Editora Planeta do Brasil, 2006.

Nas tuas mãos. São Paulo: Editora Planeta do Brasil, 2005.

Fazes-me falta. 9. ed. Lisboa: Dom Quixote, 2002. 


\section{NOTAS}

1 In: O silêncio, 1984, p. 119.

2 Diante dessa ligação indissolúvel que institui o ser e a linguagem, falar em "morte do sujeito" é um modo retórico de se referir à extinção de uma certa subjetividade, a cartesiana, como uma forma histórica de subjetivação dominante em nossa cultura.

3 Referenciado por HARVEY, David.

4 Trata-se de uma novíssima geração que vem agregando outros nomes.

5 Em outro artigo, eu me indaguei se a ditadura não era um fenômeno puramente machista, a que se opunha uma realidade utópica de realização a ser alcançado por um processo de libertação análogo ao que as mulheres tentavam em relação aos seus parceiros opressores.

6 Júlia e sua paixão pelo piano, se inspira na personagem da escritora, artista de "outro" tipo de teclado, o do computador, e, nesse sentido pode ser um alter ego diferido de T.G. Também Lídia e Hortense praticam a arte como exercício de libertação, de que falamos em outro artigo. 